\title{
Organic foliar fertilizer to improve yield of cayenne pepper (Capsicum frutescens L.) grown off-season
}

\author{
I Komang Damar Jaya*, I Wayan Sudika, Mery Windarningsih, and Mulat Isnaini \\ Faculty of Agriculture University of Mataram, Jl. Majapahit 62 Mataram 83125, Indonesia
}

\begin{abstract}
Information on the most suitable and high-yielding cayenne pepper variety for an off-season growing in dryland is important. This research aimed to examine the effect of foliar fertilizer on growth and yield of off-season cayenne pepper in dry land. The experiment was conducted during the rainy season of 2020/2021 in a dryland with a sandy loam soil texture in the area of Gumantar, North Lombok, Indonesia. Four cayenne pepper varieties, namely Dewata 43 F1, Pelita F1, Taruna, and Sret, were treated with three concentration levels $(0 \%, 0,5 \%$, and $1,0 \%)$ of organic foliar fertilizer. The treatments were arranged in a factorial randomized block design with three replications. The results revealed that application of foliar fertilizer increased number of flowers and yield, and reduced flower abortion. Pelita F1 yielded the highest, $11.5 \%$ higher than Dewata $43 \mathrm{~F} 1$ and three-fold higher than that of the non-hybrid varieties when treated with $1.0 \%$ of fertilizer. Dewata F1 was harvested at 70 days after transplanting (dat), followed by 76, 105 and 105 dat for Pelita F1, Sret and Taruna, respectively. To maximize the use of the rainfall and prolong the harvest time, Pelita F1 and Taruna varieties are highly recommended for dryland areas.
\end{abstract}

\section{Introduction}

The importance of cayenne pepper or chili (Capsicum frutescens L.) in the life and economy of Indonesian people is undisputed. Cayenne pepper is one of the main seasonings in every Indonesian dish which is also rich in nutrients and vitamins. Apart from its vitamin and mineral content, cayenne pepper and other chili species are also rich in phytochemicals and dietary fibers [1]. Because of these benefits and ingredients, the demand for cayenne pepper nationally continues to rise in line with the increase of population. Unfortunately, cayenne pepper production is very unstable throughout the year for several reasons. Most chili species do not grow optimally in conditions of excess water [2] or lack of water, although the effect varies depending on the genotype [3]. With the limiting growing environment, chili plants are mostly cultivated in the dry season on irrigated lands. This condition results in limited availability of chilies in the market during the rainy season that makes the price of chilies can be very high.

\footnotetext{
* Corresponding author: ikdjaya@unram.ac.id
} 
Soil type in dry land areas in Gumantar, North Lombok dominated by sandy soils. This soil type is very suitable for growing chilli in rainy season, since water drainage is good [4]. Chilli cultivation in rainy season is expected to fulfil the chill needs, and avoid fluctuation of chilli price. However, chilli cultivation in rainy season facing many obstacle, such as high pest and disease attacks. Other problems that arfe faced are low nutrient availability due to nutrient leaching [5] and the potential for a high percentage of flower abortion [6]. To overcome these constraints, it is necessary to look for varieties of chilies that are adaptive to high humidity conditions and have high productivity.

With regard to the agrocological conditions, farmer in the dry land area in North Lombok usually grow maize in the rainy season. However, the production and the income of maize farmers in that area is strongly affected by rainfall patterns [7]. On the other hand, the global rainfall patterns have recently changed as a result of climate change effects [8]. Therefore, it is necessary to find solutions for farmers on the dryland of North Lombok to increase their income and welfare. Planting cayenne pepper in the rainy season is one of the options. However, the soil fertility has low content of organic matter, which is less than $1 \%$ [7]. Soils with low organic matter content generally have a low nutrient availability [9]. Given the problem of low availability and low efficiency of nutrients used in dryland sandy soils, the provision of nutrients through leaves can be applied. The application of plant nutrients through leaves, especially organic nutrients, was reported to increase the growth and yield of horticultural crops [10].

In addition to the need for nutrients, the suitability of cayenne pepper varieties for planting outside the season must also be considered. Earlier study results showed that different genotypes of chili plants responded in different ways to waterlog conditions [2]. Furthermore, it was also conveyed that cayenne pepper decreased its photosynthetic activity if it experienced a waterlog stress [11] which had an impact on plant productivity. A high rainfall intensity can also affect the number of flower abortions, which in turn affects the number and the weight of fruits per plant. Different varieties show different responses in terms of weight and number of fruits per plant as affected by rainfall [12]. From all the above facts, it is very important to choose varieties of cayenne pepper that are high yielding and adaptive for off-season production in dryland areas. There are two types of superior varieties of cayenne pepper that are available in the markets, the hybrid type, and the open pollinated (OP) type. The hybrid varieties of cayenne pepper generally have an earlier harvest date than the OP varieties. This study, therefore, aimed to examine the growth and yield of hybrid and OP superior varieties of cayenne pepper grown off-season on dryland with an organic foliar fertilizer treatment.

\section{Materials and method}

\subsection{Experimental site and materials}

This experiment was conducted during the rainy season of 2020/2021 at Gumantar village, sub-district of Kayangan, North Lombok regency, West Nusa Tenggara Province, Indonesia $\left(8^{\circ} 15^{\prime} 12^{\prime}\right.$ 'S, $\left.116^{\circ} 17^{\prime} 17^{\prime} \mathrm{E}\right)$. The rainfall pattern during the experiment period (November 2020 to March 2021) is presented in Figure 1. Chemical properties of the soil at the experimental site were as follow pH $6.9\left(\mathrm{H}_{2} \mathrm{O}\right)$, C-organic (Walkey and Black) $0.9 \%, \mathrm{~N}$ total (Kjeldalh) $1.0 \%$, available P (Spectro) $91.30 \mathrm{ppm}$, and available K (Amonium acetate) $1.33 \mathrm{Meq} \%$. The soil belongs to sub-ordo Entisol and the texture was sandy loam $(14.72 \%$ clay, 40.28 silt and $45.0 \%$ sand). The maximum and minimum temperatures recorded were $38^{\circ} \mathrm{C}$ and $24.8^{\circ} \mathrm{C}$, respectively with an average of $29.8^{\circ} \mathrm{C}$. Meanwhile, the highest and the lowest relative humidity were $91.8 \%$ and $53.3 \%$ respectively with an average of $77 \%$. 


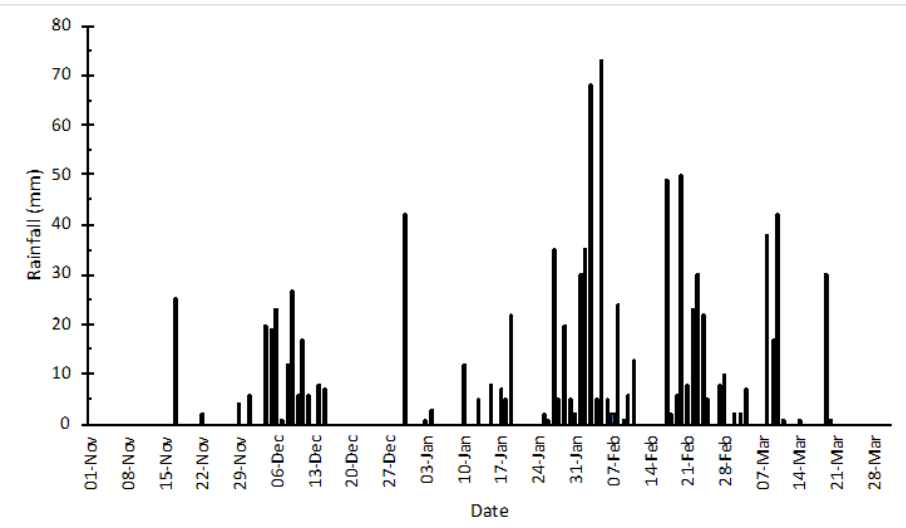

Fig. 1. Rainfall pattern in the experimental site during the course of the experiment

Four superior cayenne pepper varieties used were two hybrids (Pelita F1 and Dewata 43 F1) and two open pollinated (OP) varieties (Taruna and Sret). Foliar organic fertilizer used contain C-organic 15\%, N, P, K, some essential micro nutrients, Bacillus sp., Lactobacillus sp., Saccharomyces sp., Streptomyces sp., Pseudomonas sp., Azospirillium sp., Azotobacter sp. and Rhizobium sp.. Pesticide which contain dimehipo $510 \mathrm{ml} / \mathrm{l}$ and abamectin $18 \mathrm{ml} / \mathrm{l}$, and fungicide which contain difenokonazol $125 \mathrm{~g} / \mathrm{l}$ and azoksistrobin $200 \mathrm{~g} / \mathrm{l}$ were used.

\subsection{Experimental design and measurements}

The experiment was arranged in a factorial randomized block design with three replications. The first factor was cayenne pepper variety, while the second factor was concentration of foliar fertilizer. The varieties tested in this study were Pelita, Dewata 43, Taruna, and Sret, while the concentration had three levels: $0,0.5$, and $1.0 \%$. The size of each experimental plot was $7.6 \times 1.0 \mathrm{~m}^{2}$ to accommodate 30 plants in two rows. Three plants taken as sample plants in each treatment plot.

Variables measured were plant height and number of leaves at the first harvest, days to the first harvest, number of flowers, percentage of flower abortion, number of fruits and fruit weight per plant. The number of flowers and percentage of flower abortion were counted weekly started from the flowering date (when 50\% of the plant population in each treatment plot had produced flowers). The flowering date for Dewata 43, Pelita, Taruna, and Sret was 35, 41, 56, and 56 days after transplanting (dat), respectively. The number of fruits and fruit weight per plant was counted weekly since the first harvest date. The final measurement for all variables reported in this study was 128 dat. All the collected data were subjected to analysis of variance at 95\% confident interval and continued with Duncan's Multiple Range Test (DMRT) for that showed significant effects.

\subsection{Crop culture and management}

Seedlings were established in seedling trays for 30 days, up to 4 true leaves were formed. The seedlings then were transplanted into the treatment plots with $60 \mathrm{~cm}$ spacing between rows and $50 \mathrm{~cm}$ inside the row. Before transplanting, the plot treatments were fertilized with a basal fertilizer of NPK (15-15-15) Phonska at a dose of $900 \mathrm{~kg} / \mathrm{ha}$. The fertilizer was buried evenly in the middle of each treatment plot then a black plastic mulch was applied to cover all the treatment plots. A month after transplanting, each crop received $200 \mathrm{ml}$ of 
diluted NPK Phonska with a concentration of 3.0\%. The application was repeated every two weeks up to the end of the experiment. The total NPK Phonska fertilizer applied up to the end of the experiment was $1200 \mathrm{~kg} / \mathrm{ha}$ [13]. Irrigation was applied once, a day before transplanting, and the next water requirement for the crops was solely from rainfalls.

The foliar fertilizer was applied first at two weeks after transplanting and then repeated every two weeks with concentration according to the treatments. The last foliar fertilizer application was at 16 weeks after transplanting. Pesticide was applied every two weeks.

\section{Results and discussion}

Rainfall during the experimental period was sufficient to support the water requirement of cayenne pepper. No irrigation was provided except during transplanting. However, the plants experienced a slight wilting during the vegetative growth stage as a result of a 13-day dry-spell in December 2020 (Fig. 1). Relatively high rainfalls occurred during the flowering and fruiting period. The temperature and relative humidity at the experimental site were relatively optimum for the production of cayenne pepper. However, growth and yield of the pepper were slightly disrupted as a result of yellow curl virus attack in all tested varieties.

Table 1. Effect of variety and foliar fertilizer concentration on plant height, number of leaves and days to first harvest.

\begin{tabular}{|c|c|c|c|}
\hline & \multicolumn{3}{|c|}{ Variables } \\
\hline Treatments & $\begin{array}{c}\text { Plant height } \\
(\mathbf{c m})\end{array}$ & $\begin{array}{c}\text { Number of } \\
\text { leaves }\end{array}$ & $\begin{array}{c}\text { Day to first } \\
\text { harvest (dat) }\end{array}$ \\
\hline Variety & & & \\
\hline Dewata 43 & $58.0 c^{*}$ & $142.3 b$ & $70.0 c$ \\
\hline Pelita & $51.5 c$ & $174.6 a$ & $76.0 b$ \\
\hline Sret & $72.6 b$ & $193.0 a$ & $104.4 a$ \\
\hline Taruna & $82.6 a$ & $197.5 a$ & $104.6 a$ \\
\hline & & & \\
\hline Fertilizer (\%) & & & $89.2 a$ \\
\hline 0.0 & $62.8 a$ & $161.9 b$ & $89.0 a$ \\
\hline 0.5 & $67.5 a$ & $179.2 a b$ & $88.4 a$ \\
\hline 1.0 & $68.2 a$ & $189.4 a$ & \\
\hline
\end{tabular}

*Values in the same column and treatment that followed by the same letter are not significantly different according to Duncan's Multiple Range Test at 95\% confidence level. dat: days after transplanting.

Plant height measured at first harvest was affected by variety but not by concentration of foliar fertilizer (Table 1). The OP varieties (Taruna and Sret) showed differences in plant height, of which the Taruna variety was taller than the Sret. Both the OP varieties were taller than the hybrid varieties (Dewata 43 and Pelita). Meanwhile, there was no difference in plant height between Dewata 43 and Pelita. Plant age at the time of the first harvest was also influenced by the variety but not by the concentration of fertilizer. The earliest date for the first time to harvest was reached by Dewata 43 variety and the latest was recorded in the two OP varieties (Table 1). Plant height and time to first harvest are influenced by genetic and environmental factors. This has been shown in the previous study with the similarity in the value of genotypic coefficient variations and phenotypic coefficient variations in plant height and time to first flowering in some chili lines [14]. On the other hand, the heritability value of plant height and plant age at the first harvest was higher than $75 \%$, indicating the dominant roles of genetics [15]. Since the growing environment for the plants (soil, temperature, relative humidity, and rainfall) was the same, genetic was considered to determine the difference in plant height and age of the first harvest. 
The number of leaves at the first harvest was affected by the variety and concentration of fertilizer (Table 1). The number of leaves in Pelita, Sret and Taruna varieties was relatively the same but higher than that of the Dewata 43 variety. Previously, it was shown that Dewata 43 variety was taller than Pelita variety. These data indicated that Pelita variety had a denser canopy than Dewata 43. Earlier studies have shown genetic and environmental influences on leaf area, leaf length, and width [15] but studies linking genetics and phenotypes to leaf number in cayenne pepper are very limited. Research related to the number of leaves of the pepper plant is more directed to treatments of plant cultivation technology, such as the height of planting bed and weed control methods [16]. However, the number of leaves is closely related to the leaf area of the plant so that the character of the leaf area may be used as a reference to represent the character of the number of leaves. Genetic factors have a very high role, with heritability values close to $90 \%$ in determining the leaf area of cayenne pepper [15].

Table 2. Effect of variety and fertilizer concentration on number of flowers and percent flower abortion.

\begin{tabular}{|c|c|c|c|c|}
\hline Variables & & \multicolumn{3}{|c|}{ Foliar fertilizer (\%) } \\
\hline \multirow{4}{*}{ Number of flowers } & Variety & $\mathbf{0 . 0}$ & $\mathbf{0 . 5}$ & $\mathbf{1 . 0}$ \\
\cline { 2 - 5 } & Dewata 43 & $97.9 \mathrm{~d}^{*}$ & $130.8 \mathrm{c}$ & $161.43 \mathrm{ab}$ \\
\cline { 2 - 5 } & Pelita & $95.2 \mathrm{~d}$ & $146.0 \mathrm{bc}$ & $180.0 \mathrm{a}$ \\
\cline { 2 - 5 } & Sret & $57.8 \mathrm{e}$ & $62.0 \mathrm{e}$ & $63.8 \mathrm{e}$ \\
\cline { 2 - 5 } & Taruna & $58.8 \mathrm{e}$ & $65.2 \mathrm{e}$ & $67.6 \mathrm{e}$ \\
\hline \multirow{4}{*}{ Flower abortion (\%) } & Dewata 43 & $31.0 \mathrm{a}$ & $27.1 \mathrm{abc}$ & $23.1 \mathrm{~cd}$ \\
\cline { 2 - 5 } & Pelita & $30.7 \mathrm{ab}$ & $23.3 \mathrm{~cd}$ & $13.4 \mathrm{e}$ \\
\cline { 2 - 5 } & Sret & $24.2 \mathrm{bcd}$ & $23.7 \mathrm{~cd}$ & $22.5 \mathrm{~cd}$ \\
\cline { 2 - 5 } & Taruna & $23.4 \mathrm{~cd}$ & $27.2 \mathrm{abc}$ & $18.1 \mathrm{de}$ \\
\hline
\end{tabular}

*Values in the same variable that are followed by the same letters are not significantly different according to Duncan's Multiple Range Test at 95\% confident level.

Variety and fertilizer concentrations interacted in affecting the number of flowers and the percentage of flower abortion. Pelita variety produced the most flowers when given foliar fertilizer at a concentration of $1.0 \%$ and the lowest number of flowers was produced by the Sret variety treated with fertilizer at a concentration of $0 \%$ (Table 2). Pelita variety showed the best response to fertilizer treatment as indicated by an increase in the number of flowers by $89 \%$, followed by Dewata 43 , Taruna and Sret with values of $65 \%, 15 \%$ and $10 \%$ respectively. It seems that there is no relation between number of leaves and number of flower in this study since the hybrid and the OP varieties had different times of flowering. The low value in the number of flowers in the OP varieties (Sret and Taruna) as a result of fertilizer foliar fertilizer treatments was partly due to the data collection period. As previously stated, the two hybrid varieties (Dewata 43 and Pelita) had a much earlier flowering date than the two OP varieties (Sret and Taruna).

In general, the data showed that the higher the concentration of foliar fertilizer applied, the fewer occurrence of flowers abortion (Table 2), except for a little inconsistency in the Taruna variety. This fact showed that the macro and micro nutrients as well as microbial consortium contained in organic foliar fertilizer played a role in increasing the number of flowers and flower strength of cayenne pepper in the rainy season. As previously stated, the hybrid varieties started to produce their flowers at the age of 35 and 41 dat for Dewata 43 and Pelita varieties, respectively. Meanwhile, Taruna and Sret varieties started to produce flowers at the age of 56 dat. In the rainfall data presented in Fig. 1, it can be seen that during the flowering period, from January to February 2021, the total rainfall received was $349 \mathrm{~mm}$ with 21 rainy days. The high rainfall intensity causes flower abortion [12], as seen in most varieties treated with $0 \%$ foliar fertilizer (Table 2 ). This condition indicated that the 
application of NPK Phonska fertilizer to the soil (1200 kg/ha) was not sufficient for the cayenne pepper plants. Earlier has been stated that soils with a sandy loam texture have a low nutrient use efficiency and the possibility of high nutrient leaching in high rainfall conditions [5], as occurred in the flowering period of plants. Therefore, an additional plant nutrition in the form of foliar fertilizer is needed to reduce the number of flower abortion.

Table 3. Effect of variety and fertilizer concentration on number of fruits and fruit weight per plant.

\begin{tabular}{|c|c|c|c|c|}
\hline Variables measured & & \multicolumn{3}{|c|}{ Fertilizer (\%) } \\
\hline \multirow{4}{*}{ Fruit number/plant } & Variety & $\mathbf{0 . 0}$ & $\mathbf{0 . 5}$ & $\mathbf{1 . 0}$ \\
\cline { 2 - 5 } & Dewata 43 & $81.6 \mathrm{c} *$ & $109.0 \mathrm{c}$ & $134.5 \mathrm{ab}$ \\
\cline { 2 - 5 } & Pelita & $79.4 \mathrm{~d}$ & $121.7 \mathrm{bc}$ & $150.0 \mathrm{a}$ \\
\cline { 2 - 5 } & Sret & $43.8 \mathrm{e}$ & $47.3 \mathrm{de}$ & $49.4 \mathrm{de}$ \\
\cline { 2 - 5 } & Taruna & $45.1 \mathrm{de}$ & $47.5 \mathrm{de}$ & $55.0 \mathrm{de}$ \\
\hline \multirow{4}{*}{ Fruit weight/plant (g) } & Dewata 43 & $97.6 \mathrm{~d}$ & $130.8 \mathrm{c}$ & $161.4 \mathrm{ab}$ \\
\cline { 2 - 5 } & Pelita & $95.2 \mathrm{~d}$ & $146.4 \mathrm{bc}$ & $180.0 \mathrm{a}$ \\
\cline { 2 - 5 } & Sret & $66.5 \mathrm{e}$ & $73.2 \mathrm{de}$ & $79.0 \mathrm{de}$ \\
\cline { 2 - 5 } & Taruna & $73.0 \mathrm{de}$ & $76.9 \mathrm{de}$ & $89.2 \mathrm{de}$ \\
\hline
\end{tabular}

*Values in the same variable that are followed by the same letters are not significantly different according to Duncan's Multiple Range Test at 95\% confident level.

Pelita variety treated with fertilizer, an organic foliar fertilizer with a concentration of $1.0 \%$ produced the highest number of fruits and the lowest was recorded in Sret variety treated with $0 \%$ of fertilizer (Table 3 ). There was no significant difference between the number of fruits in the two hybrid varieties treated with fertilizer at a concentration of $1.0 \%$. Both of the hybrid varieties responded well to the additional nutrients provided by foliar fertilizer. The higher the concentration was applied; the more fruit was produced. However, this was not the case with the OP varieties, Taruna and Sret. The number of fruits per plant produced was relatively the same between those that received fertilizer concentrations of $0 \%, 0.5 \%$ and $1.0 \%$. This shows that the OP varieties were less responsive to the effect of the external treatments. The same result was shown by an earlier study on one of the OP varieties in Indonesia, Bara. This variety produced relatively the same number of fruits when was grown in three different environments [17]. Other studies showed that the number of fruits variable in cayenne pepper has a high heritability value, around $97 \%$, which means that the genetic influence is very large [17]. However, the phenotypic coefficient of variation and genotypic coefficient of variation for the number of fruits per plant variable is relatively the same, around $19.5 \%$. This shows that there is an equal opportunity between genetic and environmental factors to influence the number of fruits [18]. Another factor that might contribute the difference in the number of fruits between hybrid and OP varieties was the end of the data collection. The hybrid varieties had a much longer harvest period (54 and 48 days for Dewata 43 and Pelita, respectively) and only 24 days for the OP varieties at the end of the experiment. The number of fruits of the OP varieties was still increasing at that stage.

There was a strong positive correlation between the number of flowers and the number of fruits $\left(r^{2}=0.99\right)$ and the number of fruits with fruit weight $\left(r^{2}=0.98\right)$. Meanwhile, the correlation between the percentage of flower abortion and the number of fruits was negative, with a value of $r^{2}=-0.30$ (Table 3 ). Pelita variety produced the highest fruit weight per plant when treated with fertilizer at a concentration of $1.0 \%$ but was not significantly different from Dewata 43 variety with the same fertilizer treatment. The lowest fruit weight was produced by Sret variety with $0 \%$ of fertilizer, but it was not significantly different to the fruit weight of the plants in both OP varieties treated with higher fertilizer concentrations. The number of fruits in the two OP varieties was also not significantly different in all fertilizer concentration treatments. This indicates that the 
hybrid varieties responded well to the additional nutrients from an organic foliar fertilizer of fertilizer, to produce higher yields than OP varieties, especially when they were grown out of season on sandy loam soil in dryland.

\section{Conclusions}

We found that growth and yield of cayenne pepper was significantly affected by variety and foliar fertilizer application. The highest yield was reached by hybrid varieties treated with fertilizer at $1.0 \%$ concentration.

\section{References}

1. T.L. Olatunji, A.J. Afolayan, Food Sci Nutr. 6, 2239-2251 (2018)

2. L.J. Ou, X.Z. Dai, Z.Q. Zhang, X.X. Zou, Photosynthetica. 49, 339-345 (2011).

3. U.L. Sahitya, M.S.R. Krisna, R.S. Deepthi, Plant Cell Biotechnol. Mol. Biol. 19, 179195 (2018)

4. J. Nyamangara, L.F. Bergstro, M.I. Piha, K.E. Giller, J. Environ. Qual. 32, 599-606 (2003)

5. M. Buyinza, M. Mugagga, J. Innov. Dev. Strategy. 4, 12-17 (2010)

6. O.O. Idowu-Agida, V.O. Adetimirin, E.I. Nwanguma, A.A. Makinde, Int. J. Appl. Agric. Res. 5, 117-127 (2010)

7. I.K.D. Jaya, Sudirman, Rosmilawati, I.N. Soemeinaboedhy, I.W. Sudika, Maize yield in a dryland area as affected by rainfall variability, in IOP Conference series: Earth and environmental science, 411, 1, 012067, IOP Publishing (2020)

8. P.J.M. Cooper, J. Dimes, K.P.C. Rao, B. Shapiro, B. Shiferaw, S. Twomlow, Agric. Ecosyst. Environ. 126, 24-35 (2008)

9. D.B. Watts, H.A. Torbert, S.A. Prior, G. Huluka, Soil Sci. Soc. Am. J. 74, 1239-1247 (2010)

10. D. Haytova, Annu. Res. Rev. Biol. 3, 455-465 (2013)

11. L.J. Ou, X.X. Zou, PHOTOSYNTHETICA. 50, 49-55 (2012)

12. O.O. Idowu-Agida, D.J. Ogunniyan, E.O. Ajayi, The Afr. J. Plant. Sci. Biotechnol. 6, 50-55 (2012)

13. FAO Indonesia, http://www.fao.org/3/be829id/be829id.pdf (2013)

14. I. Sreelathakumary, L. Rajamony, J. Trop. Agric. 42, 35-37 (2004)

15. V.K. Sharma, C.S. Semwal, S.P. Uniyal, J. Hortic. For. 2, 058-065 (2010)

16. A.T. Ajibola, A. Amao, Acta fytotechn zootechny. 22, 90-100 (2019)

17. T.W.D.A. Sayekti, M. Syukur, S.H. Hidayat, A. Maharijaya, Biodiversitas J. Biol. Divers. 22, 823-829 (2021)

18. B.A. Vaishnavi, H.R. Bhoomika, G.R. Shetty, Int. J. Curr. Microbiol. App. Sci. 7, 1813-1817 (2018) 